\title{
Mnemonic abilities of primary school children with delayed mental development
}

\author{
Svetlana V. Murafa \\ Moscow State Pedagogical University, Moscow, Russia \\ Corresponding author. E-mail: murafa.svetlana@gmail.com
}

This paper presents the results of research regarding the mnemonic abilities of primary school children with developmental delays. Empirical studies of impaired mental development offer an opportunity to elucidate the psychological mechanisms underlying the process of normal development and enable us to consider at a micro level the formation of mental processes in ontogeny, which would, under normal conditions, be nondescript and not always amenable to psychological analysis. The research addresses an experimental investigation of productivity and qualitative characteristics of mnemonic abilities among primary school students with developmental delays. V.D. Shadrikov's Theory of Abilities, developed in a systemic approach framework, is the theoretical basis of the research. The method of deploying a memorization activity, as elaborated by V.D. Shadrikov and L.V. Cheremoshkina, was the investigation tool used. The sample included students in grades 1 to 4 between ages 7 to 12 and included a total of 100 children (66 boys and 34 girls). The control group of primary school students with typical development included 105 children (50 boys and 55 girls). The research consisted of several stages: a pilot study, experimental research (the test task was to memorize card \#1; the basic task was to memorize cards \#2 and \#3; to reproduce cards \#2 and \#3; and to poll the students), mathematical data processing, and a description of the levels of mnemonic ability development among primary students with developmental delays. The following procedures were employed during statistical analysis: Spearman $r_{3}$, Mann-Whitney Utest, Jonckheere-Terpstra test, and Kruskal-Wallis test.

The structure of mnemonic abilities in primary schoolchildren with developmental delays was determined to vary according to the underdevelopment of their operational mechanisms. For example, memory functions are based on the use of inborn mechanisms, and a portion of children differ in the type of underdevelopment of their perceptive abilities and attention abilities. Operational and regulative mechanisms of mnemonic abilities in primary schoolchildren with developmental delays are determined to exist at early stages of their formation. Significant differences in productivity and mnemonic abilities in primary school students with developmental delays were observed in comparison with their typically developing peers. In both children with developmental delay, as well as typical children, gender did not present any significant differences in memorization 
or the employment of functional mechanisms of mnemonic abilities. The analysis shows, and this paper discusses possible causes for subjects' inability to copy simple nonverbal material after its correct reproduction is shown.

Keywords: delay of mental development, mnemonic abilities, functional, operational, regulation mechanisms, effect of inability to redraw earlier remembered and correctly reproduced material

\section{Introduction}

Specialists of pedagogy and psychology in many countries face an urgent need to help underachieving children. In any system of education, each age period corresponds to a specific set of requirements for the level of knowledge and skills to be acquired in various school subjects. Studying the features and capabilities of children with various developmental disabilities is important for the development of psychological adjustment methods.

Children of a primary school age are known to be sensitive to the formation of study abilities and to be able to master the various forms of cooperation necessary for achieving such abilities (Mikadze \& Korsakova 1994).

Research conducted in the 1970s and 1980s by K. S. Lebedinskaya and her collaborators (Lebedinskaya, 1975; Manelis, 1999; Markovskya, 1993) was an important contribution to the study of children with limited capabilities and the development of a classification of basic types of delays in mental development. These researchers' work showed that along with emotional stubbornness and personal immaturity, such children also present non-formatted separate cognitive functions, such as programming, control functions, and left hemisphere agnostic functions (Manelis, 1999). These researchers likewise demonstrate L.S. Vygotsky's view that both normal and delayed mental development share similarities in regularity (Lybovskiy 2007; Mamaychuk \& Ilina 2004).

Papers by scholars outside Russia suggest different approaches to explaining delays in mental development. In certain cases, this phenomenon is considered part of the syndrome of "the minimal brain dysfunction" in American and British literature. The term "deficit of active attention" extends to the conditions earlier referred to as minimal brain dysfunction (Goodman \& Scott, 2008).

With the advent of genetics, the psychic began to be viewed as a reconstructed hierarchical structure integrating emerging behaviors into new, indivisible functional systems, which depend, in many respects, on the maturing of the central nervous system. In particular, researchers describe the clinical and psychological features of children with insufficient abilities to be trained (e.g., educationally disabled children with learning disabilities), shown to be able to memorize, recollect and reproduce various types of study material (Dockrell \& McShane, 1993; Fleitich-Bilyk \& Goodman, 2004).

Researching mnemonic abilities requires studying primary schoolchildren's imprinted information as a possible basis for the formation of diverse abilities such as memorization. This approach involves the analysis of the structure of imprinted information, which we understand as a system of functional, operational, and regulatory mechanisms, and allows us to uncover the mechanisms of impaired mnemonic activity among primary schoolchildren with delayed mental development. 
The aim of the present study is to test the hypothesis that in the structure of the mechanisms of impaired mnemonic activity in primary schoolchildren with developmental delays, functional mechanisms predominate, while operational and regulatory mechanisms are underdeveloped. The purpose of the study was to conduct experimental research into the structure of mnemonic abilities of primary schoolchildren with delays in mental development by investigating the productivity and effectiveness of functional mechanisms and the qualitative uniqueness of operating and regulatory mechanisms. We further hypothesized that structural differences of mnemonic abilities in children with delayed mental development and those with typical development vary within the narrow age groups of primary school and/or are affected by gender.

\section{Methods}

\section{Research methods}

The theoretical basis of our research is the theory of abilities by V.D. Shadrikov and the concept of mnemonic abilities by L.V. Cheremoshkina (Shadrikov \& Cheremoshkina, 1990). These theories conceptualize memory as mental function, positing that mnemonic abilities are properties of the same functional systems and therefore are directly interrelated. Abilities are the properties of functional systems that implement specific mental functions. Consequently, mental functions are generic forms of activity and can be described as functional activity systems.

Therefore, the productivity of mental functions can be measured by traditional parameters of productivity (productivity, quality, reliability). The parameters of an activity's efficiency can be defined by traditional properties of memory as a mental process: precision, strength, speed, volume, fast and accuracy of playback.

We can identify the main characteristics of mnemonic ability efficiency by examining certain properties of the memory parameters of mnemonic activity productivity. With regard to performance, this is the number of captured and reproduced material, or the amount of memory. In terms of quality, this is the accuracy of recording and playback. From the standpoint of reliability, this strengthens the chance of fast and accurate memorization and reproduction. In doing so, we diagnose productivity indicators of mnemonic abilities and properties of memory.

In a developed form of mnemonic ability, a system of multi-level mechanisms is implemented on the functional, operational, and regulatory levels. Functional mechanisms are innately genotypic and are conditioned upon memory, manifesting in the volume and strength of a direct imprint. The specific operating mechanisms are explained by the anatomical and morphological features of the maturing child's brain and the terms of their socialization and training. Formed in ontogeny, they are a set of memorized material-processing methods, the purpose of which are to increase speed, volume, accuracy, strength, storage and playback. Mechanisms regulating action present themselves in the aggregate planning of process memory, monitoring, and evaluation, which are interconnected with will power, motivation and emotion. Regulatory mechanisms have a significant impact on the results of mnemonic activities through operational mechanisms. Thus, the development of 
mnemonic skills - a system of functional, operational, and regulatory mechanisms - is a continuous, non-uniform and heterochronic process.

The mnemonic activity method was applied to mnemonic ability structure research (Shadrikov \& Cheremoshkina,1990) and was also the basis for the methodology of diagnostics of mnemonic abilities by L.V. Cheremoshkina. This method is concerned with studying the efficiency of mnemonic abilities, their level of development, the qualitative originality of mnemonic receptions, and means for their regulation, enabling us not only to analyze the structure of mnemonic abilities but also to identify their causes and determine their characteristics and levels of mnemonic abilities.

Meaningless nonverbal material and the order of its presentation allows us to increase the mnemonic activity while controlling for the level of productivity of functional, operational and regulation mechanisms. The experimental material (cards №1, №2, №3) is presented in picture 1 .

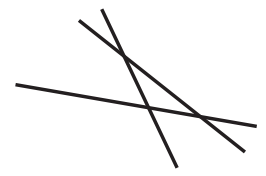

1

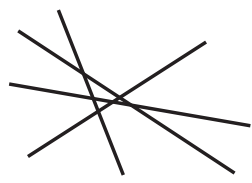

2

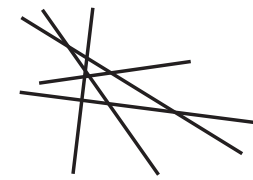

3

Picture1. Experimental material

Timing of presentation:

- Presentations 1 to 10: 1 second;

- Presentations 11 to 20: 2 seconds

- Presentations 21 to 30: 3 seconds.

Through this technique we estimated two factors:

1) The productivity of memorizing with the support of functional mechanisms, using card No. 2 (simple nonverbal senseless material);

2) The efficiency of memorizing with the support of functional and operational mechanisms, using card No. 3 (complicated nonverbal senseless material).

The times required to memorize productive figures No. 2 and No. 3 are considered qualitative indicators (Cheremoshkina \& Murafa, 2011).

\section{Stages of memorization tasks}

Stage I (trial task): memorizing and reproducing card No. 1, (given in five presentations)

Stage II (beginning of the basic task): memorizing and reproducing card No. 2. The experiment continues until the first correct reproduction of the figure is achieved. The maximum quantity of presentations is limited to 30 . The figure is considered to be correctly reproduced if it corresponds to the original figure in 
quantity of lines, quantity and character of crossings, spatial orientation and proportions.

Stage III: memorizing card No. 3 by those who have successfully performed Stage II (memorized card No. 2).

Stage IV: copying card No. 2 by all participants.

Stage V: copying card No. 3 by those who have successfully performed Stage III (memorized card No. 2).

Stage VI involves answering a questionnaire with 30 questions, allowing researchers to draw conclusions about the presence or absence of mnemonic tools, their quantity and variety, the promptness of mnemonic tool activation in the memorization process, and the degree to which a person can voluntary control his or her memorizing process.

The assessment scale for the tasks of memorizing cards \#2 and \#3, the list of questionnaire items and their analyses are provided in the method description (Cheremoshkina, 2009).

\section{Statistical analysis}

The methods employed during the statistical analysis aimed to reveal significant differences between groups of participants and the presence or absence of connections between their characteristics. The Mann-Whitney U-test was used to test the hypothesis of statistical homogeneity of research and experimental groups. We implemented the Jonckheere-Terpstra test to reveal trends between age groups in changing memorization processes resulting from changes in the patterns of reliance on functional mechanisms, implementing the test within independent samples for an ordered alternative hypothesis. The Kruskal-Wallis test was used to test the hypothesis regarding the presence of age differences in memorization and was implemented with reliance on functional mechanisms and a control group from the age of 7 to the age of 12 .

\section{Description of the sample}

Experiments were conducted in schools in the Moscow region from 2006 to 2011. The subjects were 100 primary schoolchildren with delayed mental development in grades 1 to 4 in the age groups of 7 to 8 years ( 25 persons), 9 years ( 29 persons), and 10 to 12 years (46 persons). The control group contained 105 schoolchildren with 35 people in each age category. In the sample of schoolchildren with mental development there were 66 boys and 34 girls, while the control group contained 50 boys and 55 girls.

The results of the pilot research, carried out in 2006, showed appreciable variability of productivity of mnemonic abilities in primary schoolchildren with delayed mental development. The students were allocated to groups displaying characteristics of typical cognitive abilities among primary schoolchildren with delayed mental development. To confirm the results, a basic experiment was conducted in 2007.

The diagnosis of "delayed mental development" was made by a joint medical, psychological and pedagogical commission. According to the data, those children 
had either cerebral-organic or multiple etiology of delayed mental development. The children were taught according to a special correctional program intended for classes in special schools. The program was developed on the basis of methodological and didactic materials provided by the Institute of Correctional Pedagogics under the Russian Academy of Education and was adapted for the psychophysical development of children with delayed mental development.

\section{Results}

\section{Analysis of productivity of memorization with reliance on functional mechanisms of mnemonic abilities}

Comparative analysis has shown that the structure of mnemonic abilities of primary school children with delays in mental development and the control group has a different qualitative expression and productivity.

Table 1. Distribution of means in research and control groups

\begin{tabular}{|c|c|c|c|c|c|c|c|c|}
\hline \multirow[b]{2}{*}{ Parameters } & \multicolumn{2}{|c|}{ 7- 8 y.o. } & \multicolumn{2}{|c|}{9 y.o. } & \multicolumn{2}{|c|}{ 10-12 y.o. } & \multicolumn{2}{|c|}{ 7- 12 y.o. } \\
\hline & $\begin{array}{l}\text { Dev. } \\
\text { delay }\end{array}$ & Control & $\begin{array}{l}\text { Dev. } \\
\text { delay }\end{array}$ & Control & $\begin{array}{l}\text { Dev. } \\
\text { delay }\end{array}$ & Control & $\begin{array}{l}\text { Dev. } \\
\text { delay }\end{array}$ & Control \\
\hline $\begin{array}{l}\text { Number of partici- } \\
\text { pants, total }\end{array}$ & 25 & 35 & 29 & 35 & 46 & 35 & 100 & 105 \\
\hline $\begin{array}{l}\text { Number of partici- } \\
\text { pants who perfor- } \\
\text { med the task } \\
\text { successfully, \% }\end{array}$ & 56 & 97 & 66 & 97 & 83 & 100 & 71 & 98 \\
\hline $\begin{array}{l}\text { Mean time of me- } \\
\text { morization, sec }\end{array}$ & 26,14 & 12,15 & 26,53 & 19,18 & 23,32 & 11,31 & 24,73 & 14,18 \\
\hline $\begin{array}{l}\sigma, \text { standard devia- } \\
\text { tion of time of } \\
\text { memorization, sec }\end{array}$ & 19,17 & 12,68 & 17,68 & 16,87 & 16,39 & 10,62 & 17,12 & 13,93 \\
\hline
\end{tabular}

Table 1 and Picture 1 depict the distribution of average results regarding the productivity of memorization and the building of functional mechanisms of mnemonic abilities in the sample populations.

A comparison of the results of a simple non-verbal memory intervention using nonsense material and control groups revealed that the percentage of those who coped with the first task (card No. 2) in the control group is significantly lower in the intervention groups than that of the control group: for the 7-to 8-year-olds, $56 \%$ and $97 \%$, respectively; for the 9 -year-olds, $66 \%$ and $97 \%$, respectively; and for the 10 - to 12 -year-olds, $83 \%$ and $100 \%$, respectively.

The researchers isolated and examined control group schoolchildren in groups of 7 - to 8-year-olds, 9-year-olds, and 10- to 12-year-olds for a more in-depth analysis of their mnemonic abilities.

The following is a comparative analysis of the experimental and control groups of primary schoolchildren and their productivity of memorization, building on functional mechanisms of mnemonic abilities (Table 2). 
Table2. Comparison of the productivity of memorization, building on functional mechanisms of mnemonic abilities of schoolchildren of experimental and control groups

\begin{tabular}{|c|c|c|c|c|c|c|c|c|}
\hline \multirow{3}{*}{$\begin{array}{c}\text { Productivity } \\
\text { of functional } \\
\text { mechanisms } \\
\text { of mnemonic } \\
\text { abilities }\end{array}$} & \multicolumn{6}{|c|}{ Age } & \multirow{2}{*}{\multicolumn{2}{|c|}{$\begin{array}{c}\text { All participants } \\
\%\end{array}$}} \\
\hline & \multicolumn{2}{|c|}{ 7- 8 (years), $\%$} & \multicolumn{2}{|c|}{9 (years), $\%$} & \multicolumn{2}{|c|}{$10-12$ (years),\% } & & \\
\hline & 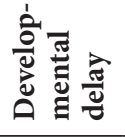 & 官 & 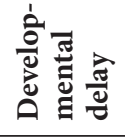 & D。 & 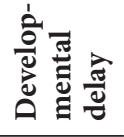 & 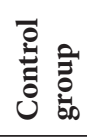 & 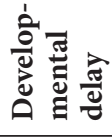 & 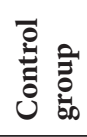 \\
\hline Very high & 7 & 35 & 11 & 29 & 16 & 40 & 13 & 35 \\
\hline High & 29 & 35 & 21 & 15 & 13 & 23 & 18 & 25 \\
\hline Above average & 14 & 12 & 5 & 15 & 26 & 25 & 20 & 18 \\
\hline Average & 7 & 9 & 21 & 17 & 8 & 6 & 11 & 11 \\
\hline Below average & 29 & 3 & 26 & 15 & 29 & 3 & 25 & 7 \\
\hline Low & 14 & 6 & 16 & 9 & 8 & 3 & 13 & 6 \\
\hline
\end{tabular}

These results suggest different specific qualitative and quantitative mnemonic abilities of schoolchildren with mental development delays compared with schoolchildren of the control group. The results obtained illustrate the considerable disorder of representative indicators of mnemonic abilities in children with delayed mental development.

The efficiency of functional mechanisms substantially impacts the time needed to memorize simple nonverbal senseless material. This indicator varies greatly: from 2 to 50 seconds for children aged 7 to 8 , from 4 to 52 seconds for children aged 9 , and from 3 to 54 seconds for children aged 12. At the same time, the presence of operational mechanisms during the memorization process differed between some subjects. These mechanisms are usually realized mainly on the perceptual, figurative and presentational levels. Regulatory mechanisms at initial stages of development were basically not diagnosed, neither in perceptual, figurative, nor representational processing.

Comparative data on the mnemonic abilities of schoolchildren with delays in mental development and control groups suggest that memorization, building on the functional mechanisms of mnemonic abilities, is typical for $71 \%$ of the children with mental retardation, and for $56 \%$ of the children in the control group. In this case, $44 \%$ of the control group children memorize the material based on the functional and operational mechanisms of mnemonic abilities.

Very high productivity of the functional mechanisms of mnemonic abilities was observer in $13 \%$ of children with delayed mental development and $35 \%$ of the children in the control group, a very high, high and above average productivity of functional mechanisms of mnemonic abilities was demonstrated by $55 \%$ of children with delayed mental development and $77 \%$ of the children in the control group. It is characteristic for children with delayed mental development to exhibit greater distributions of below average and low productivity of functional mechanisms compared to the control group: $38 \%$ and $13 \%$, respectively.

In the samples under study, the average time taken to remember simple nonverbal material (card No. 2) by schoolchildren with delayed mental development was 24.73 seconds, which corresponds to the average production of functional 
mechanisms. In the control group, this task took an average of 13.93 seconds (Figure 1) corresponding to above average productivity of functional mechanisms of mnemonic abilities.

Figure 2 graphically shows the mean value of memory productivity with support for functional mechanisms of mnemonic abilities in school children ages 7 to 8 years, 9 years, and 10 to 12 years in a group with delayed mental development (71 persons) and a control group (103 persons). We are noticing a different trend in the development of memory, drawing on the functional mechanisms of mnemonic abilities, among students in the experimental and control groups, which is qualitatively expressed in the task of remembering Card No. 2.

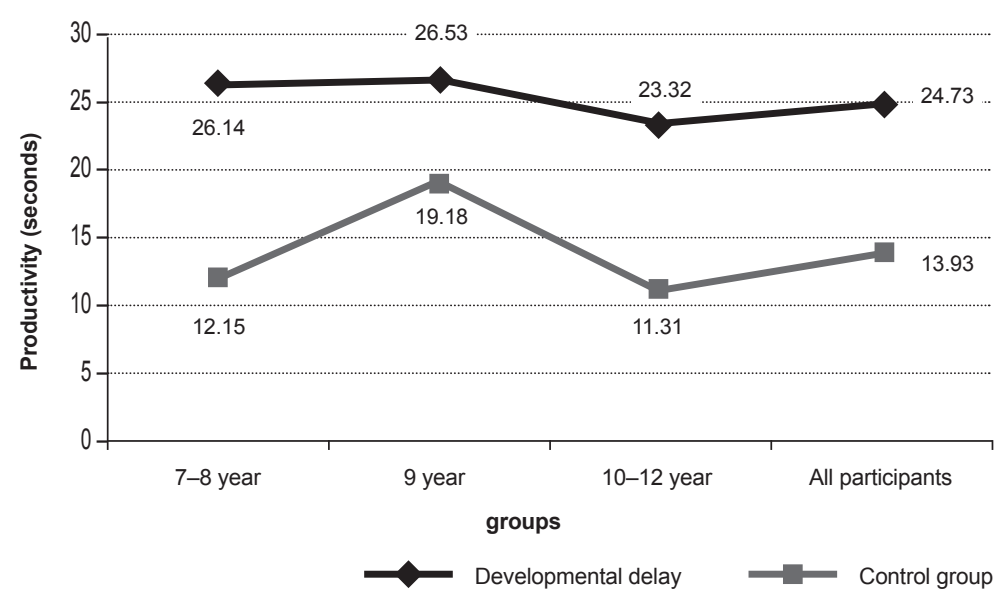

Figure 1. Memorization productivity with support for FM MS experimental and control group (in sec.).

In other words, memorization of functional mechanisms occurred at above average levels in the control group, and at average levels in the experimental group, and age did not have a meaningful effect. The rate of mental development may correspond to trends in the development memory, as drawn from the functional mechanisms of mnemonic abilities.

For example, a comparison of results obtained by schoolchildren with mental retardation to those with normal rates of mental development suggests that the abilities of students of these different groups develop along fundamentally different trajectories. It was found that the ability to engage functional mechanisms through the simple non-verbal indicators of memorizing nonsense material is much lower for children with delayed mental development than that of children with the usual rate of mental development.

Moreover, statistically significant differences were found in the store building abilities of schoolchildren when applying the U-Mann-Whitney test:

- For children with delayed mental development between 7 to 8 years, and children of the control group: $\mathrm{p}<0.5(\mathrm{p}=0.012)$;

- For children with delayed mental development between 10 to 12 years, and children of the control group: $\mathrm{p}=0.001$. 
No significant differences were found among 9-year-olds. Pupils of this age group's control group exhibited lower grades, emotional instability, inattention, distractibility in class, difficulty in concentrating when performing certain activities, and behavior problems. Highly significant difference $(p=0.000)$ was observed when comparing the abilities of experimental and control groups of 7 to 12-yearsolds (71 and 103, respectively) to remember by drawing on functional mechanisms of mnemonic abilities.

We used the H-Kruskal-Wallis test on the experimental and control groups for ages 7 to 12 years to test the hypothesis that there is an age difference in memory acquisition when relying on functional mechanisms of mnemonic abilities.

We found that there is no marked difference in the distribution of statistical time taken to memorize card No. 2 between experimental and control groups of the three independent samples of age groups 7 to 8,9 , and 10 to 12 . The level difference was $\mathrm{p}=0.747$ for schoolchildren with mental retardation and $\mathrm{p}=0.143$ schoolchildren in the control group.

We argue that the productivity of store building of functional mechanisms of mnemonic abilities does not change with age and that these mechanisms result from the genotype and congenital basis of memory. Further growth of mnemonic abilities is due to the development of certain operational and regulatory mechanisms that cause mnemonic abilities to form. This theory corresponds to existing theoretical frameworks regarding the concept of mnemonic abilities.

Furthermore, we used the S-criterion ranked alternatives by Jonckheere-Terpstra to identify trends in store building on the functional mechanisms of mnemonic abilities in the transition, from sample to sample, between ages 7 to 8 to age 9 , and from age 9 to ages 10 to 12 .

The following trends were revealed regarding the improvement of the memorization of material with age:

- Children in the 10- to 12-year-old experimental group showed the best results in storage of information from card No. 2. The next best results were by 7 - to 8 -year-olds, then 9 -year-olds.

- Children in the 7- to 8-year-old control group showed the best results in speed of memorization of card No. 2. The next best results were by of 10- to 12-year-olds, then 9-year-olds.

Analysis of the efficiency of memorization with reliance on functional and operational mechanisms of mnemonic abilities

The results of the complicated non-verbal material (card No. 3) showed that the task was completed in the control group by $23 \%$ of 7 - to 8 -year-olds, $41 \%$ of 9 -yearolds, and $66 \%$ of 10 - to 12 -year-olds, while in the experimental group only by $7 \%$ of 9- to 12-year-old schoolchildren with delayed mental development. Thus, for $44 \%$ of the children of the control group (very high, high, and higher than average level of functional and operational mechanisms of mnemonic abilities), the ability to memorize material, including training, is due to developing functional and operational mechanisms of mnemonic abilities.

A Spearman correlation test did not reveal correlational links between the time of card memorization for cards No. 2 and 3: in 7- to 8-year-olds, the correlation coefficient is 0.060 ; in 9 -year-olds, it is 0.267 ; in 10 - to 12 -year-olds, it is 0.178 . 
Consequently, the memorization of complicated nonverbal material includes mechanisms that were absent when memorizing simple non-verbal material. That is expressed in the presence of the operating mechanisms of mnemonic abilities in memorizing complicated nonverbal material.

\section{Analysis of copying of stimulus material}

An analysis of the characteristics of subjects memorizing card No. 2 revealed difficulty in copying the material already memorized, previously stored, and correctly reproduced (Figures 3 and 4 ). The effect was a failure to properly recall senseless nonverbal material after its proper storage and playback (Cheremoshkina \& Murafa, 2010, 2011). After correctly playing card No. 2, the subjects were not able to draw previously memorized and reproduced material.

The results among primary schoolchildren with delayed mental development the effect results were: $44 \%$ for 7 - to 8 -year-olds; $45 \%$ for 9 -year-olds; and $50 \%$ for 10- to 12-year-olds. For primary schoolchildren in the control group, the results were $9 \%, 9 \%$ and $3 \%$, respectively. Thus, the effect manifested in $46 \%$ of primary schoolchildren with delayed mental development and in $5 \%$ of schoolchildren in the control group.

The results of the study of productivity of mnemonic abilities were divided into four groups.

Group 1 both memorized and copied, evidencing productive functional mechanisms and just developed operational mechanisms. Mnemonic abilities of this group occurred during the second developmental level, an example of a correct task performance by examinees of Group 1 is presented in Figure 2.

Group 2 memorized but did not copy, evidencing functional mechanisms and poorly developed operational mechanisms. An example of a correct task performance by examinees of Group 2 is presented in Figures 3 and 4 .

Group 3 neither memorized nor copied, evidencing very low productivity of functional mechanisms, undeveloped operational mechanisms, and an absence of regulation mechanisms.

Group 4 copied but did not memorize, demonstrating through the correct copying of figure No. 2 the presence and development of certain perceptual and attention abilities.

There was no statistically significant difference $(\mathrm{p} \leq 0.01)$ between 10 to 12 -yearolds in groups 1 (memorized and copied) and 2 (memorized but did not copy).

\begin{tabular}{|l|c|c|}
\hline Example of card №2 & $\begin{array}{c}\text { Correct reproduction of card } \\
\text { № 2 time }=10 \text { seconds }\end{array}$ & $\begin{array}{c}\text { Correct copying } \\
\text { Participant №1 }\end{array}$ \\
\hline
\end{tabular}

Figure 2. Examples of performance of the task by the participant of Group 1 "memorized and copied" 


\begin{tabular}{|l|c|c|}
\hline Example of card No.2 & $\begin{array}{c}\text { Correct reproduction of } \\
\text { card No.2 time }=51 \text { seconds }\end{array}$
\end{tabular}

Figure 3. Examples of performance of the task by the participant of Group 2 "memorized but did not copy"

\begin{tabular}{|l|c|c|}
\hline Example of card No.2 & $\begin{array}{c}\text { Correct reproduction of card } \\
\text { No.2 time }=3 \text { seconds }\end{array}$ & $\begin{array}{c}\text { Incorrect copying } \\
\text { Participant No.3 }\end{array}$ \\
\hline
\end{tabular}

Figure 4. Examples of task performance by participants of Group 2 "memorized and didn't copy"

After analyzing the presence of delayed mental development on the options we arrived at the following result: delayed mental development characteristics of constitutional origins manifest in $32 \%$ of 8 - to 7 -year-olds, $32 \%$ of 9 -year-olds, and $31 \%$ of 10 - to 12 -year-olds. This effect is significantly less pronounced in other types of developmental delays. This result can thus be observed as a particular feature of the cognitive activity of children with delayed mental development of constitutional origin.

\section{Analysis of the interview}

The results of the questionnaire interview showed that operating machinery, association, and repetition were a strong point for only $7 \%$ of children with delayed mental development. New formations of mnemonic abilities, such as operational and regulative mechanisms, are not developed to date.

School children in the control group used a wide range of operating mechanisms: search for similarity (11\%), schematization (8\%), mnemonic planning $(26 \%)$, association $(46 \%)$, supporting point (57\%), and grouping (54\%). Operational and regulatory operating mechanisms of mnemonic abilities in this group are not yet formed.

\section{Analysis of development of mnemonic abilities per levels}

We compared the levels of mnemonic abilities through the informative results received. In the experimental group, level 1 is observed in $56 \%$ of 7 to 8 -year-olds, $59 \%$ of 9 -year-olds, and $70 \%$ of 10 to 12 -year-olds. In the control group, level 1 was observed in $77 \%, 59 \%, 34 \%$ of students, respectively. The tendency to exhibit level 
1 mnemonic abilities is greater in the experimental group and lower in the control group.

In the experimental group, level 2 begins to appear slightly for 9-year-olds (5\%), and a bit more for 10 to 12 -year-olds (11\%). In the control group, level 2 is observed in $23 \%$ of 7 to 8 -year-olds, $41 \%$ of 9 -year-olds, and $66 \%$ of 10 to 12 -year-olds in the summer school. This again proves the difference in structural organization of mnemonic abilities between children of the experimental and control groups.

The summarized structural organization of mnemonic abilities of primary schoolchildren with developmental delay, according to the results of several years of research, is shown in Figure 5.

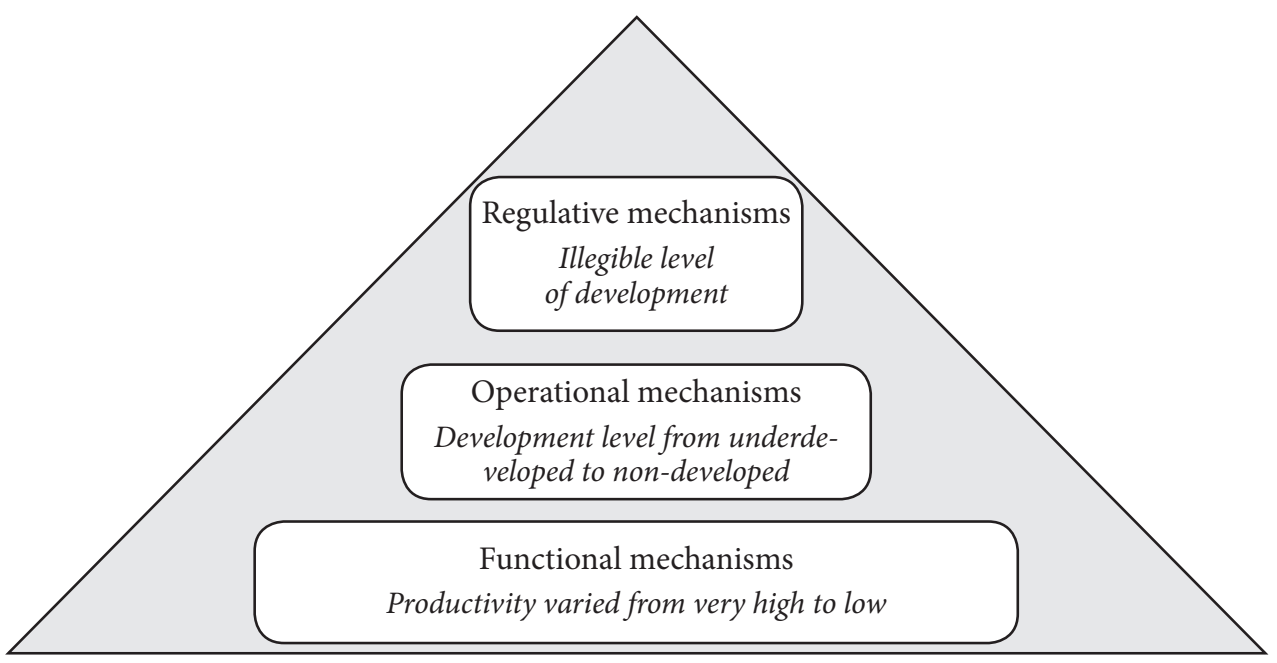

Figure 5. Structural organization of mnemonic abilities of primary schoolchildren with developmental delay

\section{Analysis of gender differences in mnemonic abilities}

The qualitative analysis also used the Mann-Whitney test to examine gender differences in among primary schoolchildren with delayed mental development and primary schoolchildren with the usual rate of mental development. Significant gender differences have not been identified in memory with support for functional mechanisms of mnemonic abilities, indicating the development of these functional mechanisms independently of gender in schoolchildren with both delayed and normal rates of mental development. The average time to remember simple nonverbal material for children with delayed mental development was 25.29 seconds for boys and 23.5 seconds for girls. In the control group these times were 15.41 seconds and 13.07 seconds, respectively.

\section{Discussion}

The structure of mnemonic abilities in primary schoolchildren with delayed mental development is significantly different from that of those with the usual rate of mental development. This is reflected in the predominance of their underde- 
veloped memory support for functional mechanisms and in the lack of regulatory mechanisms of mnemonic abilities. These abilities should be contrasted with members of the control group, who can memorize and draw based on the functional and operational mechanisms of mnemonic abilities and emerging regulatory mechanisms.

This result is not only due to defects in mnemonic ability, memory, perception and attention. The cause is found, in our opinion, in the level of the structural organization of functional systems of mnemonic, perceptual and attentional abilities.

First, we assume that violations of electoral mnemonic activity exist, accompanied by distortions, inaccuracy (substitutions), and a failure to play the stimulus material as a result of a lack of control. This may have been caused by the change of instruction ("now you are requested just to draw a card"), that is, the transition from one stage to another. Second, we noticed inertia in mnemonic activity, largely caused by dysfunction in the frontal areas of the brain that are responsible for the selection of targets and the construction of programs that control operations. Third, the dynamics of mnemonic activity may experience a breach due to a student's emotional instability as expressed in exhaustion toward the arbitrariness of the mental processes. This may explain why this effect was also observed in primary schoolchildren in the control group (Murafa, 2012).

We have not identified any references in contemporary Russian literature to the effect of inability to properly copy nonverbal meaningless stimuli after successful memorization and reproduction. We suppose this effect is a peculiar characteristic of the cognitive functions of primary schoolchildren with developmental delay.

\section{Conclusions}

The structure of mnemonic abilities among primary schoolchildren with delayed mental development is predominately based on functional mechanisms. These children's operational and regulatory mechanisms of mnemonic abilities are at the early stages of formation. The group of these students between ages 7 to 10 were able to perform memorization with reliance on the functional mechanisms of mnemonic abilities. Memorization productivity, however, was found to be significantly lower than those of children with typical development.

Productivity indicators of memorization were not impacted by changes in age, neither for 7 to 8,9 , and 10 to 12 -year-olds with delayed mental development nor for those with the usual rate of mental development. These results confirm that the functional mechanisms of mnemonic abilities are genotype and that memory is innately conditional.

We observed no gender differences in memorization with reliance on functional mechanisms of mnemonic abilities in primary schoolchildren with developmental delay and with typical development, implying the universal character of these mechanisms.

The study was contextually limited by the insufficiency of research methods for the investigation of perceptive and attention abilities, as well as by the deficiency of empirical works on conterminous issues concerning children with developmental delays. This gap may likewise be the basis for further research. 
Importantly, further systemic explanations are needed for the research results showing an inability to copy nonverbal meaningless stimuli properly after their successful memorization and reproduction. These explanations should not be limited to psychology but rather should also employ neuropsychological and neurophysiological investigation methods.

\section{References}

Cheremoshkina, L. V. (2009). Psychology of memory. Moscow: Academy.

Cheremoshkina, L. V., \& Murafa, S. V. (2010). Effect of failure to redraw previously stored material by children with mental developmental problems. Pedagogical and Psychological issues in Education-2010. (Vol. 25. pp. 162-173). Lithuania: Scientific Methodical Centre "Scientia Educologica".

Cheremoshkina, L. V., \& Murafa, S. V. (2011). Mnemonic abilities in 7-12 year old children with mental developmental problems. Voprosi Psikhologii [Issues in Psychology], 5, 34-45.

Dockrell, J., \& McShane, J. (1993). Children's learning difficulties: A cognitive approach. Cambridge: Blackwell Publishers.

Fleitlich-Bilyk, B., \& Goodman, R. (2004). The prevalence of child psychiatric disorders in Southeast Brazil. Journal of American Academy of Child and Adolescent Psychiatry, 43(6), 727-34.

Goodman, R., \& Scott, C. (2008). Child psychiatry. Moscow: Triada-X.

Lebedinskaya, K. S. (1980). Clinical types of mental retardation. Zhurnal nevrologii I Psikhiatrii [Journal of Neurology and Psychiatry], 3, 16-20.

Lybovsky, V. I. (2007). Spetsalnaya psikhologiya [Special psychology]. Moscow: Academy.

Mamaychuk, I. I., \& Ilina, M. N. (2004). Pomosch psikhologa rebenku s zaderzhkoi psikhicheskogo razvitiya [A teaching aid for psychologist dealing with children with mental retardation]. Saint Petersburg: Rech.

Manelis, N. G. (2004). Hrestomatiya po neiropsikhologii [A Reader in Neuropsychology]. Ed. E.D. Chomskaya. Moscow: Moscow Psychological and Social Institute.

Markovskaya, I. F. (1995). Zaderzhka psikhicheskogo razvitiya: klinicheskaya I neiropsikhologicheskaya diagnostika [Mental retardation: Clinical and neuropsychological diagnostics]. Moscow: Competence-Center.

Mikadze, Y. V., \& Korsakova, N. K. (1994). Neuropsychological diagnosis and correction in primary schools due to poor grades in school. Moscow: Languages.

Murafa, S. V. (2011). Produktivnost mnemicheskikh sposobnostey detey 7-12 let s zaderzhkoy psikhicheskogo razvitiya [Productivity of mnemonic abilities in 7-12 year old children with mental developmental problems]. Sibirskiy psilhologicheskiy zhurnal [Siberian Psychological Journal], 41, 42-50.

Murafa, S. V. (2012). Mnemicheskiye sposobnosti mladshikh shkolnikov s zaderzhkoy psikhicheskogo razvitiya [Mnemonic abilities of primary school children with developmental delay]. (Ph.D dissertation). Moscow: Moscow City Teachers' Training University.

Shadrikov, V. D., \& Cheremoshkina, L. V. (1990). Mnemicheskiye sposobnosti: razvitiye i diagnostika [Mnemonic abilities: Development and diagnostics]. Moscow: Obrazovaniye.

Original manuscript received March 17, 2014 Revised manuscript accepted June 15, 2015

First published online September 30, 2015 